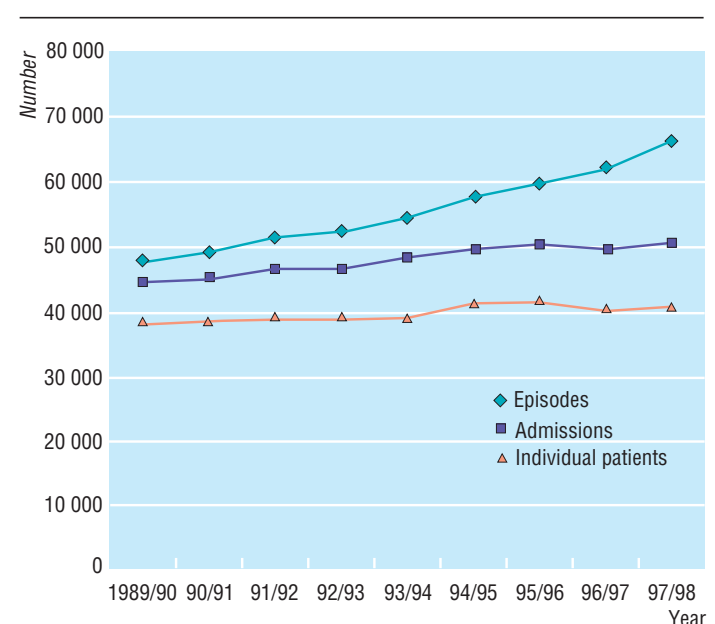

Numbers of episodes, admissions, and individual patients, 1989-90 to 1977-8, all specialties and all ages, Avon Health Authority (population 850 000)

days to 8.7 days (the median fell from 3.6 to 3.1 days). The number of emergency bed days at the beginning of the period (456382) is similar to that at the end (453 290).

\section{Comment}

This study shows that, whatever else is causing a real or perceived crisis in the NHS, an increase in the number of people requiring or demanding emergency treatment is not the explanation. The supposed rise in emergency admissions is almost entirely attributable to the increased reporting of internal transfers of patients after admission. For example, if someone with a stroke is transferred from an assessment ward to the care of a neurologist, then referred for computed tomography, and subsequently moved to a geriatric rehabilitation ward, this single admission may be recorded as three or even four episodes. Costs are attributed according to episodes, not admissions. The cost of emergency care has thus risen dramatically during a period when capacity and demand have changed little.

The main evidence to support the view that the current rise in emergency admissions may be a genuine reflection of population changes comes from the analysis of linked Scottish data for the period 1981-94. ${ }^{4}$ Our study shows how extrapolation from that period may be seriously misleading for the interpretation of more recent trends in other geographical areas. There is no doubt that many individual patients and their carers have deeply unsatisfactory experiences when seeking access to emergency care. It will be important to replicate this study in other localities to decide whether the problem in emergency care is really one of changing demand, or more a matter of the quality and accessibility of the capacity that is currently available. $^{5}$

Contributors: KM, DP, and SF jointly analysed and wrote up the study, and will act as guarantors.

Funding: None.

Competing interests: None declared.

Capewell S. The continuing rise in emergency admissions. $B M$ J 1996;312:991-2.

Blatchford O, Capewell S. Emergency medical admissions: taking stock and planning for winter. BMJ 1997;315:1322-3.

3 Frankel SJ. Health needs, health care requirements, and the myth of infinite demand. Lancet 1991;337:1588-9.

4 Kendrick S. The pattern of increase in emergency hospital admissions in Scotland. Health Bulletin 1996;54:169-83.

5 Coast J, Inglis A, Morgan K, Gray S, Kammerling M, Frankel SJ. The hospital admissions study: are there alternatives to emergency hospital admission? J Epidemiol Community Health 1995;49:194-9.

(Accepted 18 February 1999)

\title{
Use of chaperones in clinics for genitourinary medicine: survey of consultants
}

\author{
Caroline J Torrance, Robert Das, Miles C Allison
}

In 1996 the United Kingdom's General Medical Council recommended offering chaperones during intimate examinations whenever possible. This advice was incorporated into a report from the Royal College of Obstetricians and Gynaecologists. ${ }^{1}$ Surveys on chaperones have been undertaken in general practice and paediatrics. ${ }^{2-4}$ Information on the availability of chaperones and their use in hospital based adult practice is sparse. We therefore surveyed policy on the use of chaperones in British genitourinary medicine clinics, where most consultations are followed by intimate examinations.

\section{Participants, methods, and results}

In November 1996, 255 lead consultants in genitourinary medicine clinics were invited to participate in a confidential postal survey. They were asked about their departmental and hospital policies on chaperoning during genitourinary examinations in several clinical scenarios. Replies were received from 175 consultants (69\% response).

When female patients are being examined by male doctors, clinic policy is that chaperones are almost always present (table). By contrast, male nurses sometimes perform unchaperoned genital tests and treatment on female patients. Female doctors are more likely than nurses to be chaperoned while performing genital tests on female patients. Most units do not routinely use chaperones during examinations and genital tests on male patients.

Although most chaperoning is done by female nurses, one quarter of departments sometimes delegated this role to health advisers. Chaperones were sometimes relatives of patients (in 21 departments), medical students (14 departments), or secretarial or clerical staff (8 departments). Most chaperones were female, but male chaperones were used in six
Editorial by Bignall Departments of Genitourinary Medicine and Adul Medicine, Royal Gwent Hospital, Newport NP9 2UB Caroline J Torrance, clinical assistant in genitourinary medicine

Robert Das, consultant physician in genitourinary medicine

Miles C Allison, consultant physician in adult medicine

Correspondence to: Dr Allison miles.allison@ gwent.nhs.uk

BMJ 1999;319:159-60 
Numbers (percentages) of respondents whose departmental policies never, sometimes, or always provided for chaperones during performance of genital tests on female and male patients

\begin{tabular}{lccc}
\multirow{2}{*}{$\begin{array}{l}\text { Clinical scenario } \\
\text { (No of respondents to question) }\end{array}$} & \multicolumn{3}{c}{ Policy provided for chaperones } \\
\cline { 2 - 4 } & Never & Sometimes & Always \\
\hline Female patient being examined by: & & & \\
\hline Male doctor $(\mathrm{n}=165)$ & $1(1)$ & $5(3)$ & $159(96)$ \\
\hline Male nurse $(\mathrm{n}=47)$ & $14(30)$ & $5(10)$ & $28(60)$ \\
\hline Female doctor $(\mathrm{n}=159)$ & $19(12)$ & $47(30)$ & $93(59)$ \\
\hline Female nurse $(\mathrm{n}=145)$ & $81(56)$ & $52(36)$ & $12(8)$ \\
\hline Male patient being examined by: & & & \\
\hline Male doctor $(\mathrm{n}=163)$ & $74(45)$ & $44(27)$ & $45(28)$ \\
\hline Male nurse $(\mathrm{n}=95)$ & $63(66)$ & $26(27)$ & $6(6)$ \\
\hline Female doctor $(\mathrm{n}=158)$ & $38(24)$ & $55(35)$ & $65(41)$ \\
\hline Female nurse $(\mathrm{n}=128)$ & $62(48)$ & $44(34)$ & $22(17)$ \\
\hline
\end{tabular}

departments while female patients were being examined by male doctors.

Thirty seven departments were more likely to offer chaperones during examinations of patients aged under 16. Only 20 respondents said that their hospital had a policy on chaperoning. Fourteen knew of allegations of impropriety concerning medical or nursing staff in their department during the preceding five years. In the opinion of half of these respondents, allegations could have been prevented had a chaperone been present.

\section{Comment}

To our knowledge this is the first survey on chaperoning policies in genitourinary practice. Use varies widely among the respondents, and only one tenth of hospitals have a policy on chaperones. Doctors are more likely than nurses to be chaperoned while performing genital tests. The working party of the Royal College of Obstetricians and Gynaecologists concluded that a chaperone should be offered to all patients having intimate examinations in gynaecology and obstetrics, irrespective of the sex of the gynaecologist, and that if the patient declines one the response to the request should be honoured and recorded in the notes. Surveys in primary care show that many women decline chaperones. ${ }^{2}$ On the other hand, our survey identified allegations of impropriety, half of which might have been prevented by the presence of a chaperone. On this basis we believe that chaperones should be offered more widely during genitourinary examinations. Perhaps clinicians in other specialties should encourage their patients to accept chaperones during vaginal or rectal examinations.

Who should act as chaperone in genitourinary medicine clinics? Some patients (particularly adolescent females) prefer a relative to be present during pelvic examinations in general practice. ${ }^{4}$ A nurse seems better suited to the role of chaperone in genitourinary practice because he or she can help the examiner, reassure patients if they are anxious, and safeguard both parties against abuse or subsequent allegations. Many would argue that the sex of the chaperone should match that of the patient. Small clinics may face difficulty in funding nurses to fulfil this role, but costs have to be balanced against time taken to deal with complaints. Perhaps wider use should be made of auxiliary nursing staff as chaperones.

Contributors: CJT and MCA conceived the study and wrote the paper. RD designed the questionnaires, supervised their dispatch and the data analysis, and is guarantor for the study.

Funding: None

Competing interests: None declared.

1 Roval College of Obstetricians and Gynaecologists. Intimate examinations: report of a working party. London: RCOG, 1997.

2 Jones RH. The use of chaperones by general practitioners. J R Coll Gen Pract 1983;33:25-6.

3 Speelman A, Savage J, Verburgh M. Use of chaperones by general practitioners. BMJ 1993;307:986-7.

4 Penn MA, Bourguet CC. Patients' attitudes regarding chaperones during physical examinations. J Fam Pract 1992;35:639-43.

(Accepted 29 January 1999)

\section{Review of randomised controlled trials of traditional Chinese medicine}

Jin-Ling Tang, Si-Yan Zhan, Edzard Ernst

Department of Community and Family Medicine Chinese University of Hong Kong,

Shatin, New

Territories, Hong Kong

Jin-Ling Tang, associate professor in community medicine continued over

BMJ 1999;319:160-1
Many randomised controlled trials have been conducted in China to evaluate the effectiveness of traditional Chinese medicine, but much of the information is inaccessible to Western doctors. We estimated the total number of randomised controlled trials published in China and identified problems in applying such methodology to the evaluation of traditional Chinese medicine, which would serve as preparatory work for systematic review and dissemination of the randomised evidence for such medicine.

\section{Methods and results}

We randomly selected 28 journals using stratified sampling from a total of 100 Chinese journals of traditional Chinese medicine (4 national, 10 university, 10 provincial or regional, and 4 specialist journals). After special training, eight fifth year medical students (working in pairs) hand searched all the issues of the journals published before 1 January 1997 to identify randomised controlled trials. Discrepancies were settled by one of the principal investigators (S-YZ). Data on methodological quality of randomised controlled trials were extracted from 414 full length articles in the Chinese Journal of Integrated Traditional and Western Medicine. Ten times as many randomised controlled trials appeared in that journal as in the other journals, and those published in that journal were of a higher quality. ${ }^{12}$ 